\title{
Avaliação multidimensional da criatividade: uma realidade necessária
}

\author{
Solange Muglia Wechsler \\ Pontificia Universidade Católica de Campinas
}

\begin{abstract}
Resumo
A avaliação da criatividade até o momento, tem sido pautada, quase que exclusivamente, em medidas de pensamento divergente tentando-se encontrar uma forma única para a sua identificação. Nosso objetivo é demonstrar a necessidade de se avaliar a criatividade sob os mais diversos enfoques, situando a sua expressão dentro de campos específicos da sua aplicação. Uma bateria para avaliação multidimensional da criatividade é apresentada, sendo composta por dois testes internacionais. Pensando Criativamente com Figuras e Pensando Criativamente com Palavras e dois testes nacionais, de nossa autoria, Estilos de Pensar e Criar e Adjetivos Auto-descritores. O processo de validação destes instrumentos encontra-se descrito demonstrando assim a possibilidade de medir algumas das interações entre a pessoa, processo e o ambiente criativo. Concluindo, é demonstrada a importância de se buscar, cada vez mais, instrumental que atenda os parâmetros científicos da psicometria e que permita uma abordagem mais ampla, completa e multifacetada na avaliação da criatividade. Palavras chaves: criatividade, avaliação multidimensional, testes psicológicos.
\end{abstract}

\section{Summary}

Multidimensional creativity assessment: an urgent reality

Assessment of creativity has been, up to the present time, mostly based on divergent thinking measures, searching for an unique formula for its identification. Our objective is to demonstrate the need to evaluate creativity under various perspectives, focusing its expression on specific tasks. A battery of instruments to assess creativity in a multidimensional way is presented, composed by two international tests, Thinking Creatively with Pictures and Thinking Creatively with Words and two national tests, of our authorship, Styles of Thinking and Creating, and Self-descriptors Adjectives. The process of validation of these instruments is presented, demonstrating the possibility of measuring some of the interactions among the dimensions of person, process and environment as related to creativity. Concluding, it is emphasized the need to search for instruments tested under psychometry criteria, to allow for a more comprehensive understanding and multidimensional approach on the assessment of creativity.

Key words: creativity, multidimensional assessment, psychological tests.

\section{Conceituação da criatividade}

Historicamente, a criatividade foi entendida como uma forma de inspiração divina, uma dádiva concedida a poucos mortais. Encontramos também, por volta do século XVI, uma noção que perdurou durante várias décadas, equacionando criatividade como uma forma de loucura, algo incontrolável ao homem, distinguindo-o de diversos mortais, e, portanto, impossível de ser medido (Kneller,1980).

Ao redor de 1950, a importância da compreensão da criatividade foi ressaltada em um célebre discurso apresentado por Guilford à comunidade científica americana, indicando a 
necessidade de ser estudado este fenômeno devido a sua relevância para diversas áreas do comportamento humano Deste então, o tema da criatividade se tomou alvo de grande interesse para os pesquisadores, o que pode ser observado pela quantidade de publicações sobre este assunto nas últimas décadas (Isaksen \& Murdock, 1993).

Encontramos, a partir desta época, posições téoricas sobre a criatividade bastante diversas ou, até mesmo, opostas, ora relacionando-a com um processo inconsciente, gerado como um mecanismo de defesa aos impulsos sexuais, como afirmaria Freud (1958), ora explicando-a como resultante de uma cadeia de associação de idéias, como proporia Skinner (1974).

O modo de se estudar a criatividade também diferiu de acordo com a proposta téorica. $\mathrm{Na}$ teoria humanista, liderada por Rogers (1977) e posteriormente, Maslow (1968), a criatividade seria uma busca para a auto-realização, ou seja, a necessidade de desenvolvimento de potencial que todo ser humano teria dentro de si. Já na perspectiva cognitivista, destaca-se a posição de Guilford (1960), indicando que a criatividade seria uma forma de operação de pensamento do tipo divergente, podendo ser enquadrada no seu modelo tridimensional do intelecto, onde existem 120 combinações ou formas de pensar.

A visão unidimensional da criatividade foi sendo transformada, decisivamente, em finais da década de 70, tentando-se obter uma percepção mais integrada deste fenômeno através da combinação de aspectos cognitivos com os afetivos. Além disto procurou-se demonstrar a relevância e a aplicação da criatividade em vários campos da vida diária, com ênfase, primeiramente na área educacional, e, posteriormente, na organizacional.

Dentre as novas propostas de mudança desta época, visando uma ampliação do conceito de criatividade, destacam-se as contribuições do educador Paul Torrance. Este autor recebeu grande influência da abordagem cognitivista de Guilford, nos seus primeiros trabalhos ao tentar construir testes para se avaliar a criatividade verbal e figurativa (Torrance, 1966). Na sua proposta mais conhecida, à nível internacional, Torrance seguiu as mesmas dimensões de Guilford para medir a criatividade, ou seja, fluência, flexibilidade, originalidade e elaboração.

A partir de 1980, Torrance demonstrou a sua insatisfação com a pouca amplitude dos conceitos utilizados para avaliar a criatividade nos seus testes, na medida em que reduziam a criatividade apenas ao pensamento divergente. A partir daí, propôs e realizou pesquisas sistemáticas sobre onze indicadores que estariam avaliando não só os aspectos cognitivos como também os emocionais da criatividade, além daqueles já conhecidos na sua proposta inicial, e que poderiam ser verificados nos seus testes de criatividade figurativa. Os indicadores propostos foram: a presença de emoção, fantasia, movimento, combinações de idéias, resistência ao fechamento, perspectiva incomum, perspectiva interna, humor, riqueza de imagens, colorido de imagens e títulos expressivos (Torrance e Ball, 1980).

Apesar da vasta quantidade de estudos que Torrance (1990 desenvolveu a seguir sobre estes novos indicadores da criatividade, demonstrando inclusive a sua validade e precisão para predizer a criatividade na área figurativa, os testes de Torrance continuam ainda serem avaliados, em vários lugares do mundo, pelas características tradicionais, contrariamente à propostas deste pesquisador. Nota-se que este autor não realizou propostas para a verificação de novos indicadores, cognitivos e emocionais, na área da criatividade verbal, o que foi, posteriormente, foco de nossos estudos (Wechsler, 1981).

A ampliação do conceito de criatividade gerou uma série de encontros e congressos internacionais 
sobre o tema, ressaltando-se o de 1990, na Universidade de Buffalo Nesta oportunidade, foram reunidos os especialistas das mais diversas palies do mundo para discutir o estado da alie em criatividade, e buscar uma definição consensual sobre a mesma. Uma conceituação bem abrangente foi proposta, sendo a criatividade entendida como o resultado da interação entre processos cognitivos, características de personalidade, variáveis ambientais e elementos inconscientes (Wechsler, 1993). Os pesquisadores destacaram, já nesta ocasião, a importância de se avaliar a criatividade nas mais diversas formas, considerando o seu aspecto multidimensional.

A partir desta época, mais e mais, a atitude frente à criatividade começou a ser modificada, passando a ser vista como algo desejável e necessário para diversos tipos de ambientes, sejam eles educacionais ou empresariais. Fala-se mais de um "viver criativo" nos dias de hoje, valorizando, portanto, a questão não só de solução de problemas e eficácia no trabalho, como também de saúde mental (Conde, 1995).Surgem inúmeros questionamentos sobre a maneira tradicional de se estudar a criatividade, isolando-se ou dissociando-se os elementos cognitivos dos afetivos. O comportamento criativo não pode ser entendido como sendo simplesmente o resultado do pensamento ou de habilidades cognitivas, mas sim deve ser visto de uma forma mais global, onde aspectos afetivos desempenham um papel decisivo na sua expressão, entendo-se assim a criatividade como um processo mais global, dependendo do vínculo entre o cognitivo e o emocional (Rey \& Martinez, 1989; Wechsler, 1993,1995).

A busca de um modelo de saúde mental, onde se proporia a criatividade como forma de enfrentamento de problemas tem sido um dos focos de nossos estudos. Como ajudar o indivíduo criativo a encontrar a sua realização dentre de uma sociedade que resiste ao novo e ao diferente? De que maneiras fortificá-lo internamente e lhe oferecer estratégias para combater os paradigmas e resistências do seu meio, seja ele familiar ou profissional?

Conceituamos, portanto, a criatividade em uma abordagem mais ampla, onde são necessárias diversos tipos de interações para que seja completada de forma harmônica não só para o indivíduo como também para a sociedade. Neste sentido, devem ser consideradas todas as possíveis combinações entre os seguintes elementos: a) habilidades cognitivas; b) características de personalidade; c) elementos ambientais. A combinação harmônica destas variáveis permitira o alcance da auto-realização, considerando não só os aspectos pessoais, profissionais e mesmo transcendentais do desenvolvimento humano.

Diversos são os enfoques que podem ser tomados no estudo da criatividade, considerando cada um dos aspectos mencionados. Assim sendo, da mesma maneira que, no enfoque atual, sobre a inteligência podemos situar e discorrer sobre as múltiplas inteligências (Gardner, 1993), também podemos nos referir às múltiplas criatividades ou múltiplas formas de ser e atuar criativamente. É, portanto, mais adequado e correto pensar em um modelo multidimensional para se avaliar a criatividade, que busque explicar vários dos seus componentes do que se preocupar em encontrar uma medida única de criatividade válida para todas as ocasiões e que possa explicar todas as criatividades.

Infelizmente, o desenvolvimento histórico da criatividade, como já apresentado, levou a uma visão reducionista dos seus componentes, direcionando os estudiosos para uma busca de seus aspectos isolados ou específicos. Como decorrência deste fato, um erro bastante comum na produção científica nesta área, é a equação ou comparação, de forma exclusiva, da medida de criatividade com a de pensamento divergente (Isaksen, Firestien, Murdock, Puccio \& Treffinger, 1994).

\section{A medida da criatividade}

A possibilidade de se medir ou avaliar a criatividade foi demonstrada pelo célebre discurso 
de Guilford para a sociedade científica americana, já comentado anteriormente. Deste então, um grande quantidade de medidas foram desenvolvidas visando avaliar, sob as mais diversas formas, os componentes da criatividade. Em uma revisão exaustiva sobre o assunto, realizada por lsaksen, Firestien, Murdock, Puccio \& Treffinger, (1994), foram selecionadas 250 medidas de criatividade, consideradas como atendendo à determinados parâmetros científicos.

Ao abordamos o tema da avaliação, podemos citar as medidas informais e as formais. Considerando a criatividade, as medidas informais são aquelas realizadas, basicamente, pelo julgamento popular, ao considerar algo diferente, interessante, atraente, inovador. Estas medidas, não necessariamente, atendem a qualquer critério padronizado. Quanto ao aspecto formal, por outro lado, a avaliação da criatividade apresenta desafios de outra magnitude pois deve atender a certos critérios básicos científicos, apresentando pesquisas ou provas confirmando o valor da medida. Assim sendo, a compreensão da criatividade deve ser vista sob dois ângulos principais, de natureza qualitativa, com a sua metodologia própria, como também do quantitativo, atendendo aos parâmetros da psicometria.

A avaliação qualitativa da criatividade tem sido realizada através da análise das biografias de grandes gênios da humanidade, observações ou entrevistas livres. A importância deste tipo de abordagem como uma etapa geradora de hipóteses sobre a pessoa, o processo e o produto criativo foi enfatizada por Yau (1995), ao revisar estudos que utilizaram esta abordagem. Entretanto, na maioria das vezes, o conhecimento gerado através deste método deve ser refinado, posteriormente, pelos critérios mais restritivos da pesquisa quantitativa.

A avaliação quantitativa, na área da avaliação psicológica, deve seguir os parâmetros da psicometria que estabelece como requisitos básicos as provas científicas de validade e precisão do instrumento. Desta forma, deverá ser demonstrada, através de pesquisas empíricas, de que formas o intrumento mede o construto proposto e se esta medida pode ser considerada como consistente. (Anastasi, 1988).

A problemática da avaliação da criatividade quanto aos pré-requisitos de validade e precisão têm sido colocadas por vários pesquisadores da área (Torrance, 1966, Treffinger \& Paggio, 1972, Wechsler, 1993, Alencar, 1996). Como adequar as medidas da criatividade aos parâmetros da psicometria, ao considerar a complexidade da sua dimensão?

Na questão da validade de conteúdo, por exemplo, que é aquela que afirma que o teste deve ser uma amostra significativa da área que pretende medir, temos o dilema de que uma pessoa pode ser criativa de diversas forma, sendo, portanto, impossível de se retirar uma amostra do universo das capacidades criativas de uma população, como afirma Torrance ( 1966). Vemos assim a necessidade, já afirmada, de restringir o campo da medida de criatividade à forma na qual ela está sendo avaliada, ou ao campo específico ao qual se destina, se queremos encontrar a validade de conteúdo para as suas medidas.

Quanto a validade preditiva do conceito de criatividade, novamente nos deparamos com a medida critério a ser utilizada. Qual a definição de criatividade no futuro a ser comparada com a medida atual. Na literatura científica, os testes "Pensando Criativamente com Figuras e Pensando Criativamente com Palavras", têm sido os instrumentos mais utilizados para comparar o desempenho atual do indivíduo com critérios de sucesso em diferentes campos da vida (Torrance, 1995), tendo sido encontradas correlações positivas e significativas em estudos que variaram de 9 meses a 22 anos. Considerando as próprias limitações destes dois testes, Torrance tem buscado, incessantemente, outras formas para avaliar a criatividade musical, corporal, afetiva, estilos criativos etc, embora estes outros instrumentos não sejam tão conhecidos ou tão pesquisados quanto 
os dois primeiros (Torrance, 1966, Torrance, Taggal1 \& Taggart, 1984, Torrance, Khatena \& Cunnington, 1986).

Outro importante aspecto a ser considerado na avaliação da criatividade refere-se a precisão ou consistência da sua medida. Também este é outro aspecto que levanta bastante dificuldades ao serem consideradas duas principais dúvidas dos pesquisadores: a) é a criatividade é um traço humano estável? ; b) qual é a influência da motivação nas medidas de criatividade? (Treffinger \& Paggio, 1972). Apesar destas dificuldades, os pesquisadores tem tentado averiguar a precisão dos seus instrumentos, destacando-se, novamente, o trabalho de Torrance $(1966,1990)$.

\section{A avaliação multidimensional da criatividade}

Os desafios para a avaliação da criatividade são oriundos das mais diversas fontes, abrangendo desde os aspectos teóricos quanto a sua verificação empírica, utilizando diferentes tipos de medida.

O caminho a ser percorrido aponta, sem dúvida para um trabalho inconstante visando compreender a multiplicidade de elementos que compõem a criatividade. Uma abordagem multifacetada, interacionista e ecológica parece ser, portanto, a melhor maneira de abordar e investigar este construto. Neste sentido, é necessário não só compreender os aspectos culturais que influenciam e determinam os modos de ser e de expressar a criatividade, como também ir além das barreiras geográficas em busca de traços universais que possam explicar melhor este fenômeno.

Esta tem sido a nossa proposta de trabalho, visando investigar maneiras múltiplas de se compreeender a criatividade. Com esta finalidade, temos buscado apoio não só de medidas internacionais reconhecidas na área da criatividade, como também nos dedicado a construir instrumentos a partir de dados da nossa cultura. Assim sendo, estamos empenhados na organização de uma "Bateria Multidimensional de Criatividade", cuja conceituação teórica e pesquisas será apresentada a seguir.

\section{Bateria Multidimensional de Criatividade}

A nossa bateria de testes para a avaliação multidimensional da criatividade pe composta, atualmente por quatro instrumentos, sendo dois internacionais e dois nacionais, de nossa autoria.

Este conjunto de medidas visa avaliar aspectos cognitivos e afetivos relacionados com a criatividade, ou seja, da pessoa e do processo criativo e a interação entre estes dois conjuntos. A forma de avaliar a criatividade por esta bateria, refere-se aos aspectos de sentir e de se comportar como pessoa criativa, como também à expressão da criatividade em duas áreas específicas, a saber, a criatividade expressa em palavras e em desenhos. Outras formas de se avaliar a criatividade ainda pretendem ser investigadas, mais profundamente, como por exemplo, a criatividade corporal, musical, ambiental, etc, já tendo sido desenvolvidos alguns estudos iniciais neste sentido, por meio de teses e dissertações, entre nossos orientados (Wechsler, 1995).

Os instrumentos internacionais escolhidos foram os testes "Pensando Criativamente com Figuras e Pensando Criativamente com Palavras", criados por Torrance (1966, 1990). A escolha destas medidas deve-se à vasta quantidade de publicações utilizando estes instrumentos, à nível internacional e também no Brasil, demonstrando a sua validade e precisão para a avaliação da criatividade (Torrance, 1996). Os instrumentos nacionais, de nossa criação, foram denominados "Estilos de Pensar e Criar" e "Adjetivos auto-descritores". O processo de construção e validação 
destes instrumentos será descrito a seguir.

A conceituação do termo "Estilos" refere-se à maneiras preferenciais de pensar e agir em determinada situações. Assim sendo, pretendesse caracterizar certas tendências no comportamento e sentimento da pessoa criativa que não excluem, necessariamente, outros tipos de respostas à determinadas situações. A proposta do termo "Estilos de Pensar e Criar" traz uma possibilidade de se estudar a interação entre processo e a pessoa criativa, evitando assim a investigação isolada destes aspectos, e facilitando a compreensão do modo de agir da pessoa criativa dentro de um determinando ambiente.

A procura por determinados "estilos" nas pessoas criativas já têm sido alvo de várias pesquisas internacionais, como por exemplo Kirton (1989), que destaca dois estilos criativos principais: o inovador e o adaptador. Outra proposta para investigação dos estilos criativos, mais direcionada para os aspectos cognitivos, foi realizada por Stenberg e Grigorenko (1997), baseandose em um enfoque teórico da auto-regulamentação da mente, e formulando assim três tipos básicos de estilos: legislativo, executivo e judicial.

Embora estas abordagens indiquem que existe a possibilidade de se distinguir estilos de pessoas criativas, elas são, a nosso ver, bastante limitadas para a compreensão da dinâmica da pessoa e do seu processo criativo, motivo pelo qual decidimos pela criação de nosso próprio instrumento.

Outra preocupação que norteou os nossos trabalhos refere-se á própria avaliação das pessoas criativas, em relação as suas características de personalidade. Apesar de existirem alguns instrumentos que usem adjetivos contrastantes para permitir a auto-avaliação de indivíduos, pouco existe na literatura em criatividade, utilizando-se este método para a pessoa criativa. Na revisão sobre procedimentos de avaliação da criatividade, realizada por lsaksen, Firestien, Murdock, Puccio e Treffinger (1994), nenhum instrumento com formato de escala de adjetivos é apresentada como sendo especificamente direcionada para pessoa criativa, e que atenda aos critérios psicométricos. Esta foi, portanto, a decisão pela construção de um instrumento direcionado para este aspecto.

\section{Método}

\section{Sujeitos}

\section{Amostra 1}

A primeira amostra foi composta de 100 sujeitos, sendo 50 indivíduos considerados altamente criativos e 50 como regulares. O critério utilizado para a criatividade foi a produção reconhecida por meio de recebimento de prêmios à nível regional ou nacional.

Os sujeitos totalizaram 37 do sexo feminino e 63 do masculino, idade variando de 18 a 70 anos, representando diversos níveis culturais. Os sujeitos foram escolhidos aleatoriamente na região do estado de São Paulo, representando as seguintes áreas: literatura, artes plásticas, publicidade, esporte, música, artes cênicas, dança, empreendimentos técnico-científicos.

Esta amostra foi considerada para validade preditiva dos instrumentos estudados.

\section{Amostra 2}

Esta amostra foi composta por 1000 sujeitos, sendo 500 do sexo feminino e 500 do sexo masculino, com idades variando de 18 a 65 anos, representando os três níveis sócioeconômicos. Os sujeitos foram escolhidos aleatoriamente dentre diversas cidades do estado de São Paulo. 
Esta amostra ficou posteriormente reduzida a 736 sujeitos (390 masculinos e 346 femininos) devido ao número de testes devolvidos com itens em branco ou com respostas duplicadas.

\section{Instrumentos}

\section{a. Pensando criativamente com palavras}

(Torrance, 1966, 1990)

Trata-se de um teste destinado a avaliar a criatividade figurativa do indivíduo, expressa por meio de desenhos realizados com estímulos diversos. O instrumento é composto por três atividades principais. A primeira apresenta uma forma curva como estímulo, a segunda possui rabiscos, de diversos tipos, para serem completados e a terceira tem uma série de linhas paralelas como proposta inicial para desenhos.

O teste é avaliado por características cognitivas e emocionais apresentadas nos desenhos e nos seus títulos.

As seguintes dimensões são avaliadas: I) Fluência: quantidade de idéias; 2)Flexibilidade: diversidade na categoria de idéias; 3) Originalidade: idéias incomuns; 4) Elaboração: quantidade de idéias; 5) Expressão de emoções: sentimentos expressos nos desenhos; 6) Fantasia: seres imaginários nos desenhos; 7) Combinação: síntese de estímulos; 8)Movimento: expressão de ação nos desenhos; 9) Perspectiva incomum: desenhos feitos em perspectiva; 10) Perspectiva interna: desenhos vistos por dentro; 11) Contexto: ambiente para os desenhos; 12) Títulos expressivos: imaginação nos títulos; 13) Índice criativo: junção das características.

\section{b. Pensando criativamente com palavras \\ (Torrance, 1966,1990)}

Este instrumento é composto por seis atividades que visam medir a capacidade criativa verbal do indivíduo, sendo composto por seis atividades. Nas três primeiras atividades, é pedido que o sujeito faça perguntas, adivinhe causas e conseqüências relacionadas a uma situação apresentada. Na quarta atividade, é pedido que se proponha melhorias em um elefante de brinquedo, na quinta atividade a tarefa é propor novos usos para caixas de papelão e na sexta é pedido que sejam adivinhadas conseqüências para uma situação descrita.

O autor desenvolveu a proposta de serem avaliadas três características criativas verbais neste instrumento (Fluência, Flexibilidade, Originalidade). Nossos estudos demonstraram a possibilidade de se investigar outras características verbais (Wechsler, 1981, 1993).

As dimensões avaliadas neste instrumento são: 1) Fluência: quantidade de idéias; 2) Flexibilidade: diversidade de idéias; 3) Originalidade: idéias incomuns; 4) Elaboração: detalhamento das idéias; 5) Emoção: expressão de sentimentos; 6) Perspectiva incomum: perguntas fora do estímulo; 7) Fantasia: menção à entidades imaginárias; 8) Analogias: uso de comparações; 9) Índice criativo verbal: soma das características.

\section{c. Estilos de pensar e criar}

Este instrumento foi construído em forma de escala contendo 100 itens relacionados aos estilos preferenciais de pensar e criar dos indivíduos. Os itens foram construídos baseados na literatura sobre as características das pessoas criativas, avaliando 25 dimensões. Cada dimensão é investigada por quatro itens, sendo dois de forma positiva e dois negativos. 
A escala é feita em formato de likert de 6 pontos, na seguinte pontuação: discordo totalmente, discordo, discordo parcialmente, concordo parcialmente, concordo e concordo totalmente.

As dimensões avaliadas pela escala são: fluência, flexibilidade, originalidade, sensibilidade interna e externa, fantasia, inconformismo, independência de julgamentos, abertura à novas experiências, analogias e metáforas, idéias elaboradas, preferências por situações de risco, alta motivação, humor, impulsividade e espontaneidade, confiança em si mesmo, sentido de um destino criativo, persistência, otimismo, sensibilidade ambiental, curiosidade, honestidade, energia, liderança, tolerância à frustração, visionário.

\section{d. Adjetivos auto-descritores:}

Este instrumento foi composto de uma pergunta aberta, onde era solicitado ao indivíduo que apontasse dez adjetivos que melhor o descrevessem. Posteriormente era solicitado que fossem circulados três adjetivos, dentre os dez apresentados, que fossem a sua melhor descrição.

\section{e. Questionário de dados pessoais:}

Este questionário serviu como base para seleção da amostra, sendo composto por perguntas abertas para verificar se o sujeito tinha realizado produção criativa nas mais diferentes áreas e se tinha recebido alguma distinção para cada uma delas.

\section{Procedimento}

Para a amostra 1 foram localizados sujeitos que atendessem ao critério de premiação no estado de São Paulo, sendo lhes solicitado que realizassem entrevistas individuais. Os sujeitos não criativos foram escolhidos ao acaso, também sendo realizadas entrevistas individuais. Nas entrevistas foram aplicados os cinco instrumentos mencionados.

Para a amostra 2 procurou-se trabalhar com grandes grupos, afim de facilitar a aplicação coletiva. Foram também realizadas aplicações individuais. Nesta oportunidade somente o teste de estilos foram aplicados.

A amostra 1 serviu como critério para validade preditiva do teste Pensando Criativamente com Figuras e Palavras e Estilos de Pensar. Também a partir dela foi baseada a construção do instrumento "Adjetivos Autodescritores", em sua forma experimental. A amostra 1 serviu para análise do construto de "Estilos de Pensar e Criar".

As análises estatísticas realizadas foram a Correlação de Pearson, o Test $T$ e a Análise Fatorial.

\section{Resultados}

O teste $T$, realizado para distinguir os grupos criativos dos não criativos, apontou resultados altamente significativos $(\mathrm{p}<0,01$ a $\mathrm{p}<0,0001)$ a para todas as características criativas verbais, com exceção de fantasias e analogias. Para a criatividade figural, todas as características criativas tiveram resultados significativos $(\mathrm{p}<0,05$ a $\mathrm{p}<0,0001)$ com exceção de fantasia e combinações. Os Índices Criativos Verbais e Figurais, que apresentam a soma das características avaliadas, demonstraram ser um potente indicador de criatividade nas áreas avaliadas, discriminando significativamente os dois grupos $(\mathrm{p}<0,0001)$. 
Na medida de estilos de pensar, a análise fatorial apresentou 7 estilos básicos, ou fatores de primeira ordem contrastando com as 25 dimensões iniciais, e um fator de segunda ordem.. Os oito estilos, compostos pela nova denominação devido à agregação dos itens, carga fatorial $>0,40$, eingvalue $>2$, foram: 1) confiança motivadora; 2) inconformismo inovador; 3) sensibilidade interna e externa; 4) investimento intuitivo; 5) síntese humorística; 6) fluência flexível; 7) tolerância parcial; 8) ousadia intuitiva

A correlação de Pearson realizada pela comparação entre estes estilos e produção criativa dos indivíduos foi altamente significativa para todos os fatores $(\mathrm{p}<0,05$ a $\mathrm{p}<0,0001)$, com exceção do sétimo, demonstrando assim a validade preditiva do construto de estilo.

A precisão observada para cada fator, medida pelo Coeficiente alpha de Cronbach, variou de 0,54 (fator 4) para 0,91 (fator 8). Portanto, podemos considerar o teste como preciso para a característica de estilo de pensar e criar.

Quanto aos adjetivos auto-descritores, foram encontrados 76 adjetivos que poderiam descrever a pessoa criativa. Um instrumento, em forma de escala, tipo likert de seis pontos, foi construído com estes adjetivos, baseando-se na nossa insatisfação de encontrar opostos perfeitos para cada adjetivo. Este instrumento passará por um processo semelhante de validação assim como foi realizado com o teste de estilos.

\section{Conclusões}

Os dados obtidos nos instrumentos apresentados demonstram a possibilidade de se avaliar a criatividade de uma maneira multidimensional. As nossa medidas apresentaram excelentes padrões de validade, à nível discriminativo e a nível preditivo.

Quanto à discriminação entre grupos criativos e não criativos, observarmos que os testes "Pensando Criativamente com Figuras" e "Pensando Criativamente com Palavras" são medidas válidas para a criatividade tanto no Brasil quanto no exterior. Assim sendo, parecem existir características específicas dos indivíduos criativos que são representadas através de seus desenhos e na sua expressão verbal.

Outro resultado importante foi o da validade preditiva da escala construída como "Estilos de Pensar e Criar". Definitivamente, podemos observar que existem estilos ou maneiras preferenciais de lidar com a informação que distinguem os indivíduos criativos dos não criativos, ao serem encontradas importantes relações entre certas maneiras de sentir ou de comportar e realizações criativas na vida real. Estes dados nos apontam a importância de certas características da personalidade criativa, ou melhor colocando, a existência de "um modo de ser criativo".

As conclusões obtidas, até o momento, nos nossos estudos, remetem para importantes aplicações para a prática almejando alcançar o desenvolvimento da criatividade. Considerando que as medidas encontradas estão altamente relacionadas com a criatividade, podemos planejar programas educacionais que visem estimular a expressão destas características nas mais diversas faixas etárias.

$\mathrm{Na}$ área educacional, estratégias devem ser planejadas que encorajem ou estimulem o aparecimento das características criativas aqui observadas nos desenhos e nas redações de crianças e jovens. Na orientação ou re-orientação vocacional, devem ser enfocados aqueles comportamentos que expressem um modo criativo de ver e lidar com a realidade, retomando a noção anteriormente expressa da alta ligação entre criatividade, saúde mental, realização pessoal e profissional. 
Por outro lado, conseguimos demonstrar neste estudo, que se é possível medir a criatividade de uma maneira fidedigna ou precisa. Assim sendo, mais e mais o fenômeno criativo sai do campo da subjetividade para ser compreendido de uma forma científica, e de alta relevância para a área do diagnóstico psicológico. Estes resultados vêm, portanto, confirmar a consistência da medida da criatividade como observado nas mais diferentes culturas.

Vários estudos ainda são necessários afim de ser conseguida uma bateria mais completa para a avaliação da criatividade. Um dos instrumentos mencionados "Adjetivos Auto-descritores", por exemplo, necessita de vários passos para a sua validação e estudo de precisão, o que pretendemos realizar nos próximos meses.

Por outro lado, necessitamos finalizar o estudo da precisão dos testes Pensando Criativamente com Figuras e com Palavras, o que será feito através do método teste-reteste afim de se avaliar a estabilidade de tais instrumentos. Somente após todos estes estudos é que seremos capazes de iniciar o processo de normatização da nossa bateria de criatividade. Pretendemos padronizar a nossa bateria em diferentes faixas etárias, partindo da idade de quinze anos, considerada por nós como faixa desenvolvimental que já permite ao indivíduo descrever a si mesmo, e a sua relevância e aplicação imediata para a área da orientação vocacional.

Necessitamos também coletar dados de outras partes do Brasil, reconhecendo a existência de várias subculturas no nosso país e a importância que o ambiente exerce sobre o modo preferencial de expressar a criatividade. Também estamos buscando equilibrar melhor os sexos dentro da amostra critério, afim de investigar se os estilos de criar são homogêneos entre os sexos ou se existem diferenças significativas neste sentido.

Outras medidas deverão ainda serem agregadas a estas medidas iniciais, indicando o nosso compromisso de apresentar um diagnóstico mais completo e possível do construto da criatividade. Pretendemos, portanto, evitar o referir-se a uma criatividade, demonstrando, cientificamente, a existência de várias criatividades.

Os desafios a serem vencidos neste caminho são diversos, passando não somente pela própria evolução deste conceito mas também pelas dimensões dos valores de uma cultura. Por outro lado, pouco ainda sabemos sobre a criatividade do povo brasileiro e as suas possibilidades, se compararmos a quantidade de publicações sobre o assunto no nosso país como a de outras nações.

O momento nos parece propício para a investigação da criatividade no Brasil, na medida em que já observamos a sua menção como algo desejável nos mais diversos ambientes e para as mais diferentes finalidades. A conceituação da criatividade está agora aliada ao funcionamento sadio do indivíduo ou a uma dinâmica de saúde mental, sendo, portanto, importante procurar o seu desenvolvimento. Cabe aos pesquisadores encontrar formas de identificar este construto, de forma ampla e multidimensional, afim de permitir que esta informação seja utilizada para colaborar na realização pessoal e profissional do indivíduo.

Existe no Brasil um sentimento ou crença de que somos um povo criativo. Resta agora aos pesquisadores apresentarem medidas com qualidade científica que possam justificar esta percepção para a nossa cultura. 


\section{Referências}

Alencar, E. S. (1996). A medida da criatividade. Em L. Pasquali (org). Teorias e métodos de medida em ciências do comportamento. Brasília: INEP.

Anastasi, A. (1988). Psychological Testing. Sixth edition. New York: Macmillan Publishing Corporation.

Conde, G. A. (1995). Multiderazgo creativo. Santiago da Compostela: Master Internacional Creatividad Aplicada Total. Monografia.

Freud, S. (1958). The relation of the poet to daydreaming. Em S. Freud. Crealivity and the unconcious. New York: Harper \& How.

Gardner, H. (1993). Creative minds: an anatomy of creativity seen through the /ives of Freud, Einstein. Picasso, Stravinsky, Eliot, Graham. and Gandhi. New Y ork: basic books.

Guilford, 1. P. (1960). The structure of the intellect model: its use and imp/ications. New Y ork: Mack Graw Hill.

Isaksen, S. G., Murdock, M. C. (1993). The emergence of a discipline: issues and approaches to the study of creativity. Em S. G. Isaksen, M. C. Murdock, R. L. Firestien \& D. 1. Treffmger. ( org). Understanding and recognizing creativity. New Jersey: Ablex Publising Corporation 13-48.

Isaksen, S. G., Firestien, R. L., Murdock, M. c., Puccio, G. J., \& Treffinger, D. 1. (1994). The assessment of creativity. Buffalo, New York: Center for Creative Studies.

Kirton, M. (1989). Adaptors and inovators: styles of creativity and problem solving. London: Routledge.

Kneller, G. F. (1978). Arte e ciência da criatividade. São Paulo: Ibrasa.

Maslow, A. H. (1968). Toward a psychology of being. New York: Van Nostrand.

Rey, F. G., \& Martinez, A. M. (1989). La personalidad: su educación y desarollo. Cuba: Editorial Pueblo y Educación

Rogers, C. (1977). Tornar-se pessoa. Lisboa: Moraes Editores.

Skinner, B. F. (1974). Sobre o behaviorismo. São Paulo: Editora Cultura.

Stemberg, R. 1. \& Grigorenko, E. L. (1994). Are cognitive styles still in style? American Psychologist, 52, 700-712.

Torrance, E. P. (1966). Torrance tests of creative thinking. Lexington: Personnel Press.

Torrance, E. P., \& Ball, O. (1980). Fourth revision: stream/ined scoring and norms for figural form A . ITCT. Athens: Georgia Studies of Creative Behavior.

Torranc, E. P., Taggart, B. \& Taggart, W. (1984). Human information procesing survey. Illinois: Scholastic Testing Survey.

Torrance, E. P., Khatena, 1., \& Cunnington, B. (1986). Thinking creatively with sounds and words. Illinois: Scholastic Testing Service. 
Torrance, E. P. (1990). Torrance tests of creative thinking. Figural forms A and B. Benseville: Scholastic Testing Service.

Torrance, E. P. (1995). Why fly? a philosophy ofcreativity. New Jersey: Ablex Publishin Corporation.

Torrance, E. P. (1996). Cumulative bib/iography on the Torrance Testsof Creative Thinking. Athens: Georgia Studies of Creative Behavior.

Treffinger, D. J., \& Paggio, J. P. (1972). Needed research on the measurment of creativity. Journal of creative behavior, 6,253-267.

Wechsler, S. M. (1981). Identifying creative strengths in the verbal forms of the Torrance tests of creative thinking. Dissertation abstracts international. 42,352Ia. University microfilms $\mathrm{n}$. 82,01588 .

Wechsler, S. M. (1993). Criatividade: descobrindo e encorajando. Campinas: Editora Psy.

Wechsler, S. M. (1994). Criatividade e saúde mental na escola. Anais do XVlI International School Psychology Colloquim / 11 Congresso Nacional de Psicologia Escolar. Campinas, São Paulo, 74-77.

Wechsler, S. M. (1995). O desenvolvimento da criatividade na escola: possibilidades e limitações. Estudos de Psicologia, 12 (I), 81-86.

Wechsler, S. M. (1996). Criatividade e psicologia escolar: implicações da pesquisa para a prática. Coletâneas da Anpepp, 1(5),53-61.

Yau, C. (1995). Qualitative research in creativity. Buffalo, New York: Creative Education Foundation Press. 